\title{
DISCUSSION
}

\section{Use of fall cones to determine Atterberg limits: a review}

\author{
BRENDAN C. O’KELLY*, PAUL J. VARDANEGA†, STUART K. HAIGH†, KATIA VANESSA BICALHO§, \\ JEAN-MARIE FLEUREAU\| and YU-JUN CUI**
}

\author{
Contribution by Katia Vanessa Bicalho, Jean-Marie Fleureau \\ and Yu-Jun Cui
}

The authors have presented a thorough and careful review in relation to laboratory tests and other approaches employed in the determination of the consistency limits of clayey soils, highlighting their use and misuse for fine-grained soil classification purposes and in existing correlations. The discussers appreciate the contributions that the authors have made on improving the fundamental interpretations of the Atterberg limits and quantitative relationships between their values and soil parameters.

The discussers would like to include some additional comments on the poor precision of the thread-rolling plastic limit (PL) measurements and evaluations of PL values of different clay minerals. It has been recognised in the literature that the procedures specified by the thread-rolling method are excessively reliant on operator skill and judgement. To investigate this point, the authors present PLs determined by different laboratories for 11 inorganic fine-grained soils of intermediate to very high plasticity. The maximum difference between the smallest and largest measured PLs in the set presented by the authors for a given soil type was $8 \%$, with an average PL of $33.8 \%$. Previous publications have reported variation up to $20 \%$ in the PLs determined in different laboratories for a given soil (Whyte, 1982). The observed differences in PL measurements can be significant, as the published data of the PLs show relatively little typical water content range in comparison with corresponding data of Atterberg liquid limits (LLs) for any clay mineral. White (1949) presented the Atterberg LL and PL values collected from the same source for two montmorillonite types: one carrying sodium as the exchangeable cation and the other carrying calcium. Note that the PLs of the two montmorillonites were about the same, but there was a great difference in the LLs, which was probably due to the type of exchangeable cation, and the two montmorillonite types may exhibit a wide range of engineering properties. These results show that the influence of PL values on the plasticity index, $I_{\mathrm{P}}$ (i.e. LL - PL), and the activity (Skempton, 1953) values in expansive clay minerals may be practically insignificant. It is then suggested that caution should be employed

\footnotetext{
* Department of Civil, Structural and Environmental Engineering, Trinity College Dublin, Dublin, Ireland.

$\dagger$ Department of Civil Engineering, University of Bristol, Bristol, UK.

+ Department of Engineering, University of Cambridge, Cambridge, UK.

$\S$ Federal University of Espirito Santo, Civil Engineering Department, Vitoria, ES, Brazil.

|| Université Paris Saclay, Centrale-Supélec CNRS, Laboratoire de Mécanique des Sols, Structures et Matériaux, Gif-sur-Yvette, France.

** Ecole des Ponts ParisTech (ENPC), Laboratoire Navier/CERMES, Champs-sur-Marne, France.
}

in using PLs collected from different sources for future empirical relationships between PL values and corresponding soil parameters.

Regarding the correlations relating to LLs obtained by the methods of percussion (Casagrande cup apparatus), $\mathrm{LL}_{\text {cup }}$, and penetration (fall-cone), $\mathrm{LL}_{\mathrm{FC}}$, the authors determined four different non-linear empirical correlations using a large database assembled from the literature, with LL obtained by different standards adopting different devices. The general empirical correlation between $\mathrm{LL}_{\text {cup }}$ and $\mathrm{LL}_{\mathrm{FC}}$ proposed by the authors can be written as

$$
\mathrm{LL}_{\mathrm{FC}}=K \mathrm{LL}_{\text {cup }}^{N}
$$

where $K$ and $N$ are fitting constants. The authors show that the fitting constants varied systematically with the material and the hardness of the Casagrande apparatus base. The observed differences were minimal for $\mathrm{LL}<60 \%$. The cone and percussion methods give LL values that differ by more than $15 \%$ for $\mathrm{LL}_{\text {cup }}=120 \%$ (Fig. 14).

Application of the authors' correlations to some experimental data of $\mathrm{LL}_{\text {cup }}$ and $\mathrm{LL}_{\mathrm{FC}}$ values ranging from 14 to $98 \%$, for different natural low-plasticity inorganic clays from Brazil, is illustrated in Fig. 14. The $\mathrm{LL}_{\text {cup }}$ tests reported by Bicalho et al. (2014) were performed for the hard rubber base cup and the $\mathrm{LL}_{\mathrm{FC}}$ obtained for the $30^{\circ}-80 \mathrm{~g}$ fall-cone. The Atterberg limits of the natural clays lie on the A-line (Casagrande, 1948) in the classical plasticity chart. The low-plasticity clays are essentially kaolinites and illites. $\mathrm{LL}_{\text {cup }}$ values are generally $2.7 \%$ lower than $\mathrm{LL}_{\mathrm{FC}}\left(\mathrm{LL}_{\mathrm{FC}}=\right.$ $\mathrm{LL}_{\text {cup }}+2 \cdot 7, R^{2}=0 \cdot 98$ ). Di Matteo (2012) reported similar results for low-plasticity inorganic fluvial-lacustrine soils from Central Italy $\left(\mathrm{LL}_{\mathrm{FC}}=\mathrm{LL}_{\text {cup }}+2 \cdot 2\right)$, with $\mathrm{LL}$ values between 20 and $50 \%$.

Experimental results obtained by Bicalho et al. (2017) on bentonite-silica fine sand mixtures with a clay fraction higher than $60 \%(C>60 \%)$ are also presented in Fig. 14; these indicate that, compared with the hard rubber base Casagrande apparatus, the cone penetrometer gives significantly higher results for highly plastic clays $\left(\mathrm{LL}_{\mathrm{FC}}=\right.$ $\left.0.9 \mathrm{LL}_{\text {cup }}-9, R^{2}=0.98\right)$. At least three replicate $\mathrm{LL}$ tests were performed by the same operator on each clay-sand mixture using the same method. The soil mixture samples were first homogenised, conditioned to a high moisture content and left to equilibrate in sealed plastic bags for several days $(>7)$. In general, the results were very consistent for a given soil mixture and method, varying within a range of about $1 \%$ in any particular set of data. The Atterberg limits of the bentonite-sand mixtures lie on the U-line defined as $I_{\mathrm{P}}=0.9$ $\left(\mathrm{LL}_{\text {cup }}-0 \cdot 8\right)$ in the classical plasticity Casagrande chart. It is assumed that for $C>60 \%$ the bentonite dominates the behaviour of clay-sand mixtures by preventing direct interparticle contact of the sand particles.

The percussion and the cone LL methods respond differently depending upon the soil clay mineralogy. If all LL experimental data are included (low- and high-plasticity clays), it can be seen in Fig. 14 that the correlation between 


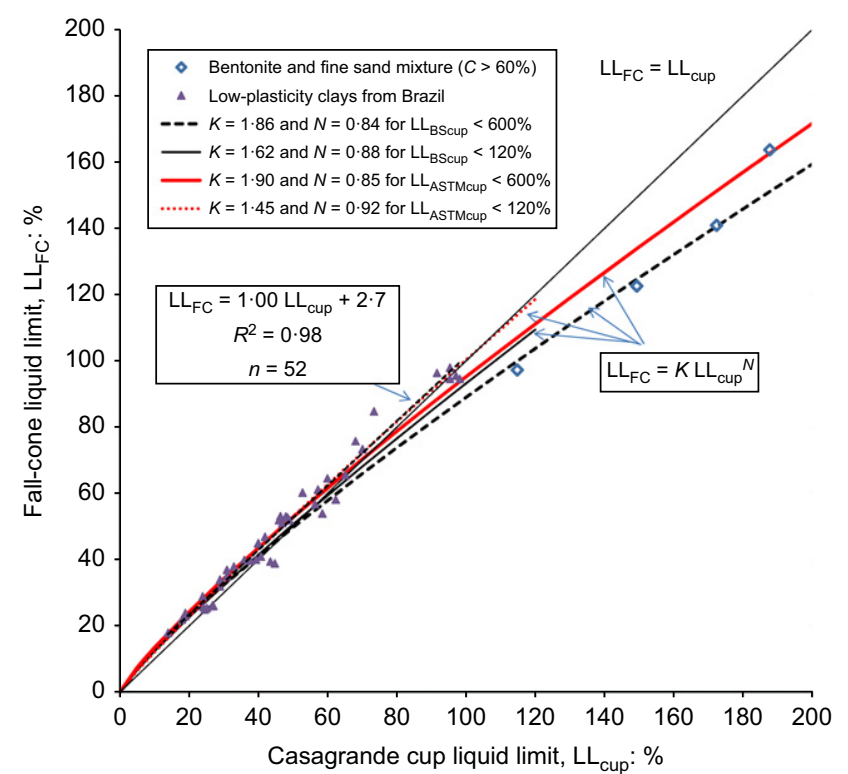

Fig. 14. Relationships between the $L L$ values obtained by the fall-cone and percussion (hard-base and soft-base Casagrande cup apparatus) methods proposed by O'Kelly et al. (2018) and experimental results reported by Bicalho et al. $(2014,2017)$ for low- and high-plasticity clays

$\mathrm{LL}_{\text {cup }}$ and $\mathrm{LL}_{\mathrm{FC}}$ is not linear at all. Although it is observed in Fig. 14 that, for the particular experimental data, some points do not coincide with the empirical correlation suggested for LLFC $_{\mathrm{FC}}$ against the ASTM 'hard base' cup

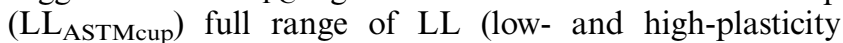
clays) - that is, $K=1.90$ and $N=0.85$ in equation (21). It is notable that the non-linear calibrations proposed by the authors represent the very large database well, especially if one considers that the equations suggested by the authors were defined from data for fine-grained soils with very different geological formations and geotechnical properties using different testing procedures by different operators and laboratories.

\section{Authors' reply}

The authors thank the discussers for their interest in the review paper (O'Kelly et al., 2018) and in this reply give further elaboration and clarification on some of the key points raised.

\section{Correlating fall-cone LL with Casagrande LL}

Regarding the correlations relating LLs obtained by the British Standard (BS) fall-cone ( $\left(\mathrm{L}_{\mathrm{FC}}\right)$ and the percussion cup apparatuses ( $\mathrm{LL}_{\mathrm{BScup}}$ and $\mathrm{LL}_{\mathrm{ASTM}}$ cup) (reported as equations (8)-(11) in the paper under discussion), the authors wish to make the following observations.

(a) It is good to see that the discussers found the non-linear calibrations given by equations (10) and (11) represented well the $\mathrm{LL}_{\mathrm{FC}}-\mathrm{LL}_{\mathrm{ASTM}}$ cup datasets of 52 natural inorganic clays from Brazil (Bicalho et al., 2014) and four silica fine sand-bentonite mixtures (Bicalho et al., 2017), neither of which were employed in the formulation of these equations. This is particularly satisfying for the authors since, as mentioned by the discussers, these equations were derived from reported data for fine-grained soils with very different geological formations and geotechnical properties, employing several LL test standards (codes) and performed by numerous operators in different laboratories.

(b) As per Fig. 14 produced by the discussers, the plotted $\mathrm{LL}_{\text {ASTMcup }}-\mathrm{LL}_{\mathrm{FC}}$ results for the four sand-bentonite mixtures $\left(\mathrm{LL}_{\mathrm{ASTMcup}} \geq 115 \%\right.$ ) reported in Bicalho et al. (2017) indicate that, compared with the hard rubber base Casagrande cup apparatus, the BS fall-cone approach gives somewhat lower LL results for extremely high-plasticity clays (not the 'significantly higher results' as stated by the discussers), as predicted by equations (10) and (11).

(c) For an LL value of $120 \%$, the largest difference in LLs predicted using the pertinent equations (9) and (11) occurs for the $\mathrm{LL}_{\mathrm{FC}}-\mathrm{LL}_{\mathrm{BScup}}$ combination at $10 \cdot 6 \%$, compared to $1 \cdot 4 \%$ for the $\mathrm{LL}_{\mathrm{FC}}-\mathrm{LL}_{\mathrm{ASTM}}$ cup combination - that is, not the 'more than $15 \%$ ' value reported by the discussers. Nevertheless, as this clearly demonstrates, the predicted differences can be considerable for higher LL values. This is especially evident in the case of the $\mathrm{LL}_{\mathrm{FC}}-\mathrm{LL}_{\mathrm{BScup}}$ combination, proving the potentially significant importance of applying these correlations - for instance, in obtaining $\mathrm{LL}_{\text {cup }}$ from measured $\mathrm{LL}_{\mathrm{FC}}$ for the purposes of deducing other soil parameters employing existing correlations derived based on $\mathrm{LL}_{\text {cup. }}$.

\section{Influence of mineralogy}

While the ratio between percussion and fall-cone LLs is generally greater than one for montmorillonitic soils and close to unity for kaolinitic soils, this does not imply, as the discussers state, that the 'percussion and the cone LL methods respond differently depending upon the soil clay mineralogy'. As can be seen from Fig. 14, the relationship between LL values is a continuous function across LLs, with no separation being seen between clays of different mineralogies, albeit that montmorillonitic soils tend to have high LL values. As shown by Haigh (2012), the increasing ratio between cup and cone LL values can be derived based on the mechanics of the two tests, cup LL being dependent on dynamic slope stability and hence affected by soil density as well as shear strength. For high-LL soils, the lower soil densities seen at LL result in lower strengths being required for stability relative to those for low-LL soils. Water contents higher than the fall-cone LL are hence seen at the percussion LL, with the form of the relationship being predictable based on analysis of the test mechanics, which also explain the difference between the results from hard- and soft-base Casagrande devices, as described by Haigh (2016). Although mineralogy may well play a key role in the varying strength of clays with water content, and hence the high LL values of montmorillonitic soils, the two LL methodologies do not respond in any way to mineralogy, rather they measure two differing physical quantities.

\section{Repeatability of the thread-rolling PL test}

In Table 1 of the paper under discussion, the authors presented an example case of consistency limits data originally reported in Sivakumar et al. (2015) for 11 inorganic, intermediate- to very-high-plasticity fine-grained soils obtained through four independent geotechnical laboratories (mean PL in the range 16.0-33.8\%). For these soils, the maximum difference in the measured PLs for a given soil type of eight percentage points occurred for the kaolin sample investigated (standard deviation (SD) of 3.6 and coefficient of variation (COV) of $10 \cdot 6$ ), although it was pointed out in the paper under discussion that Sherwood 
(1970) reported an even larger variation in measured PL for engineering practice. The discussers comment on the poor precision of PL measurements, using the example case of Whyte (1982) to suggest a variation of up to 20 percentage points in the PLs determined in different laboratories for a given soil; he reported a clay with mean PL of $23 \%$ produced PL results ranging from as low as $19 \%$ to as high as $39 \%$. No other information was reported in Whyte (1982) for the single clay material tested. Sherwood (1970) investigated the reproducibility of various geotechnical laboratory tests, including the PL, for prepared clayey sand, Gault clay and Weald clay samples having mean PLs of $18 \%, 25 \%$ and $25 \%$, respectively (based on the results of PL testing by 41 operators from different laboratories across the UK). Sherwood (1970) found that, for these three soils, the difference from the mean PL ranged from -7 to +14 percentage points, corresponding to an $\mathrm{SD}=2 \cdot 4-3 \cdot 2 \%$ and $\mathrm{COV}=12 \cdot 7-13 \cdot 1 \%(\mathrm{SD}$ and $\mathrm{COV}$ were much lower for a single operator), comparable with the findings of the Sivakumar et al. (2015) investigation. Sherwood \& Ryley (1970) reported COV values for eight operators performing $30^{\circ}-80 \mathrm{~g}$ fall-cone LL tests on sandy clay, Gault clay and Weald clay samples (mean LLs of $36 \cdot 1 \%$, $73 \cdot 5 \%$ and $65 \cdot 4 \%$, respectively) ranging from 0.93 to $3 \cdot 3 \%$. The fall-cone approach for LL is clearly less variable between operators than the thread-rolling PL test, but some measurement variation is present for both tests. Although a range of values due to measurement error and operator judgement at PL is expected, the test remains the only way of establishing the plastic-brittle transition point (Haigh et al., 2013).

\section{Correlations between PL and other soil properties?}

Referring to the example of consistency limits reported in White (1949) for sodium and calcium montmorillonites, with similar PLs but a great difference in their values of LL, the discussers make the point that the influence of PL values on the plasticity index $\left(I_{\mathrm{P}}\right)$ and activity values for expansive clay minerals may be practically insignificant. The authors agree that caution is required in using PL values collected from different sources for future empirical relationships between PL and other soil parameters. As reported in the paper under discussion, useful consistency-limit-based correlations are invariably established on $\mathrm{LL}, I_{\mathrm{P}}$ or liquidity index $\left(I_{\mathrm{L}}\right)$; for example, see equations (2)-(5) in the original paper. Given the better repeatability of the fall-cone LL test, one could argue that if there is a choice in selecting LL or PL (or $I_{\mathrm{P}}$ ) as a predictor for a geotechnical correlation, then LL is preferred; however, LL does not indicate the range of plastic behaviour, simply an assigned liquid-to-plastic transition point, and therefore it is not surprising that the PL (usually used in computing the $I_{\mathrm{P}}$ ) is also needed for many geotechnical correlations (cf. Kulhawy \& Mayne, 1990).

\section{REFERENCES}

Bicalho, K. V., Gramelich, J. C. \& Cunha, C. L. (2014). Comparison between Casagrande cup and cone penetrometer test for determining liquid limit of different Brazilian clays. Comunicações Geológicas 101, No. III, 1097-1099 (in Portuguese).

Bicalho, K. V., Gramelich, J. C., Cunha, C. L. \& Sarmento Junior, R. (2017). Study of liquid limit values determined by Casagrande cup and Cone penetrometer test for different clays. Geotecnia 140, 63-72 (in Portuguese).

Casagrande, A. (1948). Classification and identification of soils Trans. ASCE 113, No. 1, 901-930.

Di Matteo, L. (2012). Liquid limit of low- to medium-plasticity soils: comparison between Casagrande cup and cone penetrometer test. Bull. Engng Geol. Environ. 71, No. 1, 79-85, https://doi.org/ 10.1007/s10064-011-0412-5.

Haigh, S. K. (2012). Mechanics of the Casagrande liquid limit test. Can. Geotech. J. 49, No. 9, 1015-1023, https://doi.org/10.1139/ T2012-066, and Corrigenda 49, No. 9, 1116 and 49, No. 11, 1329.

Haigh, S. K. (2016). Consistency of the Casagrande liquid limit test. Geotech. Test. J. 39, No. 1, 13-19, https://doi.org/10.1520/ GTJ20150093.

Haigh, S. K., Vardanega, P. J. \& Bolton, M. D. (2013). The plastic limit of clays. Géotechnique 63, No. 6, 435-440, https://doi. org/10.1680/geot.11.P.123.

Kulhawy, F. H. \& Mayne, P. W. (1990). Manual on estimating soil properties for foundation design, Report No. EL-6800. Palo Alto, CA, USA: Electric Power Research Institute.

O'Kelly, B. C., Vardanega, P. J. \& Haigh, S. K. (2018). Use of fall cones to determine Atterberg limits: a review. Géotechnique $\mathbf{6 8}$ No. 10, 843-856, https://doi.org/10.1680/jgeot.17.R.039, and Corrigendum 68, No. 10, 935.

Sherwood, P. T. (1970). The reproducibility of the results of soil classification and compaction tests, Transport and Road Research Laboratories, Report LR 339. London, UK: Department of Transport.

Sherwood, P. T. \& Ryley, M. D. (1970). An investigation of a cone-penetrometer method for the determination of the liquid limit. Géotechnique 20, No. 2, 203-208, https://doi.org/10.1680/ geot.1970.20.2.203

Sivakumar, V., O'Kelly, B. C., Henderson, L., Moorhead, C. \& Chow, S. H. (2015). Measuring the plastic limit of fine soils: an experimental study. Proc. Instn Civ. Engrs - Geotech. Engng 168, No. 1, 53-64, https://doi.org/10.1680/geng.14.00004.

Skempton, A. W. (1953). The colloidal "activity" of clays. In Proceedings of the 3rd international conference on soil mechanics and foundation engineering, vol. 1, pp. 57-61. Zurich, Switzerland: Organizing Committee ICOSOMEF.

White, W. A. (1949). Atterberg plastic limits of clay minerals. Am. Mineral. 34, No. 7 and 8, 508-512.

Whyte, I. L. (1982). Soil plasticity and strength - a new approach using extrusion. Ground Engng 15, No. 1, 16-24. 